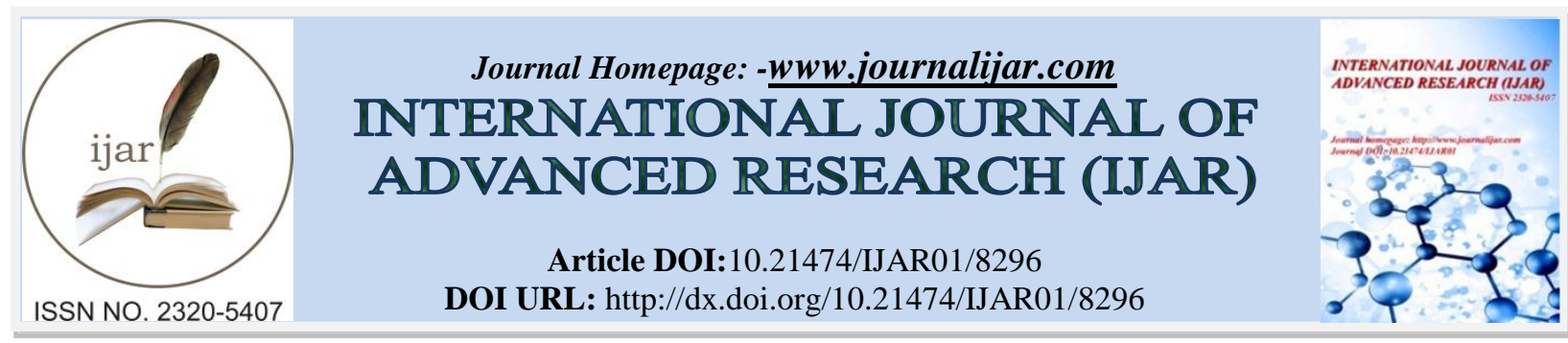

RESEARCH ARTICLE

\title{
TEMPLATE TECHNIQUE - A NOVEL APPROACH TOWARDS SMILE REJUVENATION IN UNCOMPLICATED ANTERIOR CROWN FRACTURE - A CASE REPORT.
}

\author{
Ambreena Khurshid, Sanjay Chachra, Abhishek Dhindsa, Gurpreet Kour, Samriti Bansal, Taranjot Kaur \\ and Manu Sharma.
}

\section{Manuscript Info}

Manuscript History

Received: 01 November 2018

Final Accepted: 03 December 2018

Published: January 2019

Keywords:

Dental trauma, Uncomplicated crown fracture, Composite restoration, Polyvinyl siloxane.

\section{Abstract}

Anterior teeth trauma is common phenomenon in young children and adolescents . Uncomplicated crown fracture results in loss of function, poor esthetics and psychological trauma. It is a true emergency and warrants urgent evaluation and management. This case report describes a novel approach towards smile rejuvenation in uncomplicated anterior crown fracture with direct composite restoration- template technique.

Copy Right, IJAR, 2018,. All rights reserved.

\section{Introduction:-}

Fracture of an anterior tooth due to trauma that mainly affects children and adolescents, is a common occurrence, with an incidence of $18-22 \%$ of all injuries to the dental hard tissues. About $28-44 \%$ of these cases are uncomplicated fractures, i.e. they do not involve the dental pulp [1].Uncomplicated crown fracture to the permanent teeth not only affects smile of patient, speech and function but also negatively affects self esteem and confidence of patient due to unsighty appearance.

Treating patients with anterior tooth fracture poses great difficulty to clinicians both from a functional and an esthetic perspective[2].Success of treatment modalities is dependent upon operators skills, knowledge and also on adhering to a well planned, structured and problem solving approach[3]. Extensive exploration on adhesive technology bestows the clinician with diverse alternatives to select from. The direct composite resin restoration is a simple, cost effective treatment option[1]. Direct composite has emerged as an excellent material over other direct restorative counterparts. Their evolution since their introduction in dentistry has resulted in superior properties like better bonding, optical and handling properties. Their performance has also been supported by many longevity studies [3].

\section{Case Report}

A 12 year old boy reported to the out patient department with chief complaint of broken upper front teeth and wanted treatment of same.

Patient gave history of trauma 6 months back due to fall from a bicycle. No relevant medical history was recorded. Clinical examination revealed Ellis class II (uncomplicated fracture) in relation to 11 and 21 (figure 1). Both teeth responded normally to electric pulp testing. The patient was asymptomatic without any associated soft or hard tissue injuries to the supporting tissues. Intraoral periapical radiograph confirmed the absence of pulpal or periapicalpathosis. So, it was planned to restore the fractured segment using direct composite restoration technique. Unsupported enamel was removed using 45 degree bevel to increase the surface area. Preliminary 
impressions of both the arches were made using alginate impression material (figure 2), study models were made in dental stone and mock preparation of the lost tooth structure with modeling wax was done and further checked for occlusal interference (figure 3). Once the crown build up was done, the cast was duplicated by using template putty impression material (figure 4). Labial surface of the putty template was removed up to middle third of the crown with BP blade, to aid in the reconstruction of the lost tooth structure (figure 5). A clinical try - in of the template was done to ensure adequate fit. Finally appropriate shade selection of composite material was done followed by crown build up to restore the fractured teeth quickly with minimal post-restoration finishing (figure 6).

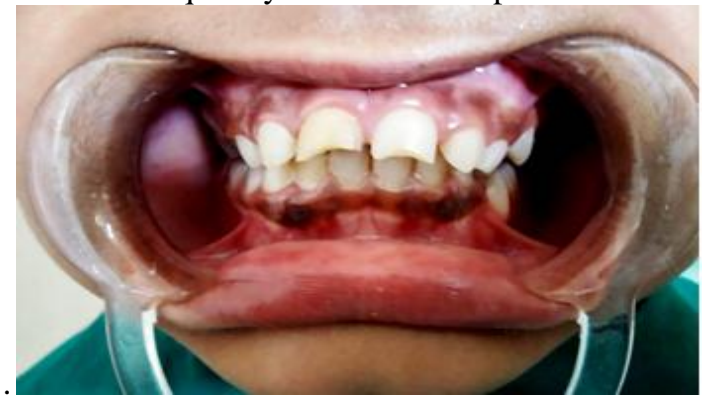

Figure 1:-Pre-operative view

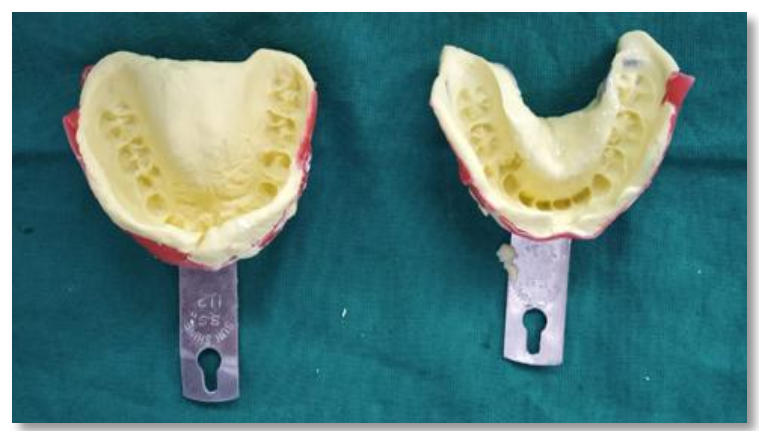

Figure 2:-Preliminary impression of upper and lower arch

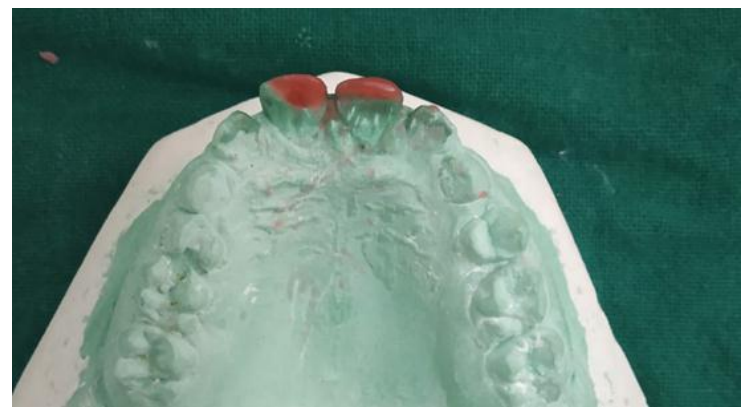

Figure 3:-Mock preparation using modeling wax

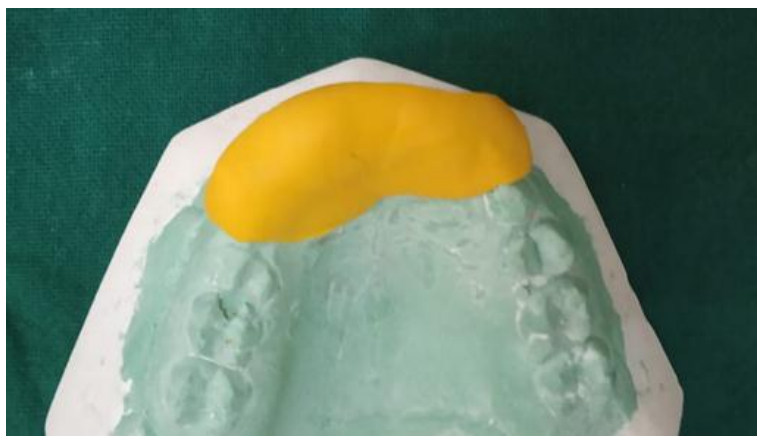

Figure 4:-Cast duplicated using Putty Impression material 


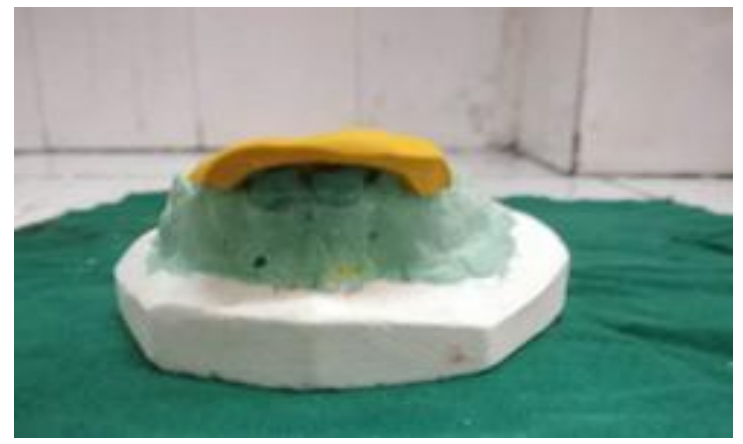

Figure 5:-Labial surface of putty template removed upto middle third of the crown

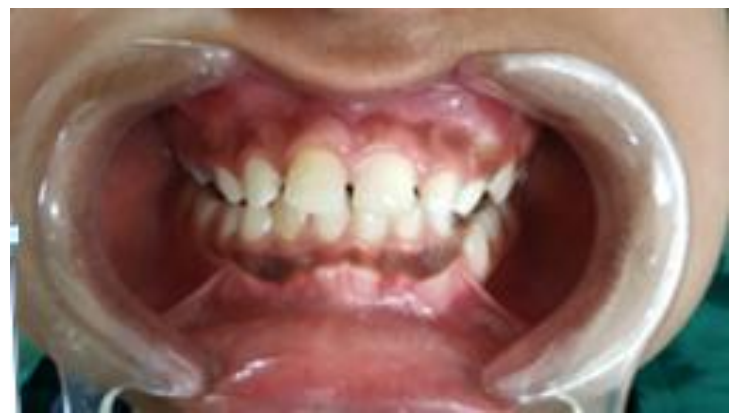

\section{Discussion:-}

Figure 6:-Post operative view

Management of fractured anterior tooth is an intricate procedure. Treatment objectives vary depending upon certain cardinal factors like age, socio-economic status of the patient and intraoral status at the time of treatment planning[4].

Various treatment alternatives are available for restoration of fractured teeth like composite restoration, fixed prosthesis, reattachment of the fracture fragment (if available) followed by post and core supported restorations[5,6,7]. Stellini E et al ., found reattachment of coronal fragments didn't restore resistance to fracture to the value of intact teeth and more over is affected by the type of composite resin utilized whereas Singhal R found fracture resistance varied 24-51\% that of an intact teeth fracture resistance[8]. Laminated veneers or full coverage restoration may be considered after multiple fragment rebonding / composite resin restorations but this option is not operational owing to loss of healthy tooth structure. Moreover clinician often faces difficulties in colour matching with adjacent un-restored teeth [8].

In the present case, age of the patient was taken into consideration as the fractured tooth was in its active eruption phase, an esthetic direct composite restoration was planned. Various techniques were considered to restore the tooth with composite restoration which includes direct technique; free hand composite restorations; indirect technique; use of preformed crowns / thermoplastic moulds as templates. Even though preformed crowns and thermoformed templates have shown satisfactory results, there are certain limitations like requisition of specialized aramamentarium like vacuum former, time consuming and most importantly proper incremental layering of composite material is not possible. Therefore in the present case a novel approach was used including both direct and indirect method by using polyvinyl siloxane (PVS) rubber base impression material (putty) as template. This technique allowed incremental layering of the composite material, optimal depth of cure, accurate reproducibility of the anatomic contours and minimal polishing and finishing[9]. Template technique can prove as a simple, economic, effective and appropriate technique that will satisfy all the requirements of dental personnel for esthetic management of anterior crown fracture[2].

\section{Conclusion:-}

Successful treatment of patients with anterior crown fracture is attributed to careful selection and manipulation of the desired composite material. Direct composite resin bonding agents successfully deal with esthetic problems of 
maxillary anterior teeth along with a painless approach providing successful outcome for the dentist and greater satisfaction for the patients.

\section{References:-}

1. Sapna CM, Kumar R, Rakesh R. Rajan, Priya R. Uncomplicated crown fracture: A biological management option . IJADS 2014; 1(1): 15-17

2. Pahuja H, Mittal GK, Agarwal S, Verma A, Tomar H. Restoring esthetics in fractured anterior teeth- Template technique. International Journal of Contemporary Medical Research 2016;3(5): 1283-84

3. Rajavardhan K, SaiSankar A.J, Tanveer SA, Kumar V , Kumar KR. A Novel Technique in Restoring Fractured Anterior Teeth. Journal of Clinical and Diagnostic Research 2014;8:244-245.

4. Terry DA. Restoring the incisal edge. NYSDJ 2005: 30-35.

5. Samadi F, Jaiswal JN, Pandey S, Bansal N. Restoration of fractured anterior teeth by using thermoformed templates - A Case Report. 2012; 1(2):2 Journal of Dentofacial sciences.

6. Terry DA. Adhesive reattachment of a tooth fragment: The biological restoration. PractProcedAesthet Dent 2003; 15(5): 403-09.

7. Fidel SR, Fidel RAS, Sassone LM, Murad CF, Fidel RAS. Clinical management of a complicated crown-root fracture: A case report. Brazilian Dent J 2011; 22(3): 258-62.

8. Singhal R, Pathak A. Comparison of the fracture resistance of reattached incisor tooth fragments using 4 different materials. J Indian SocPedodPrev Dent 2012; 30(4): 309-15.

9. Jefferies SR. The art and science of abrasive finishing and polishing in restorative dentistry. Dent Clinic North America 1998; 42(4):613-27. 10. Donly KJ, Browning R. Class IV preparation design for micro-filled and macrofilled composite resin. Paediatric Dent 1992;14(1): 34-36. 